\title{
O VÍNCULO E O DESEJO DE CASAIS E AS REPERCUSSÕES NA ADOÇÃO DO FILHO
}

\author{
Helena Raymundo ${ }^{1}$ \\ Faculdade Sumaré - SP
}

\section{RESUMO}

O presente artigo é fruto do trabalho com casais inscritos no processo de adoção do Fórum Central de São Paulo Capital, e objetiva trazer algumas considerações que nasceram a partir da escuta de narrativas dos pares, que manifestaram diferentes níveis de desejo em relação à adoção de um filho. Esta escuta ocorreu em oito encontros, com o propósito de levá-los a uma reflexão subjetiva sobre o significado da adoção para cada um dos participantes. Com referenciais teóricos psicanalíticos, buscou-se em Spivacow, a partir dos conceitos de sintonia e validação, o entendimento dos processos de aceitação e legitimação para si do desejo do outro na relação entre casais. Este artigo objetiva também, estabelecer a importância entre a validação do desejo pela paternidade/maternidade e a correlação com a formação do vínculo com o filho, em especial com o filho adotivo, e suas implicações nos processos comportamentais e de aprendizagem, a partir da teoria do vínculo de Pichon-Rivière.

Palavras-chave: desejo, vínculo, sintonia, validação, adoção, aprendizagem.

\footnotetext{
${ }^{1}$ Helena Raymundo - Socióloga, Psicopedagoga e Especialista no Atendimento de Família, Professora no Curso de Pós-graduação de "Psicopedagogia e Educação Socioemocional" da Faculdade Sumaré - SP, Voluntária no Programa Pais e Filhos do NAS - Instituto Sedes Sapientiae, junto ao Fórum Regional do Tatuapé -SP. E-mail: helenaraymundo@terra.com.br
} 


\title{
THE BOND AND DESIRE OF COUPLES AND THE REPERCUSSIONS ON THE ADOPTION OF THE CHILD
}

\begin{abstract}
This paper is the result of a survey performed with couples who were enrolled in the adoption process in the Central Forum of São Paulo, Capital. It aimed to bring considerations that came from the narratives of these couples who expressed different levels of desire regarding the adoption of a child. The narratives were recorded during eight meetings in order to lead each participant to a subjective reflexion on the meaning of the adoption. Along with theoretical psychoanalitycal references, it was searched in Spivacow's work, the understanding of the processes of acceptance and legitimization of the desire of the other within the relationship between couples, according to the concepts of connection and validation. Based on Pichon-Rivière's bond theory this paper also aimed to establish the importance between the validation of the desire for parenthood and the correlation between the bond of the child, in special the adoptive one, and the implications in the behavioral and learning processes.
\end{abstract}

Keywords: desire, bond, connection, validation, adoption, learning.

\section{Introdução}

No atendimento a grupo de casais inscritos no processo de adoção de crianças no Fórum Central João Mendes Jr de São Paulo, pode-se perceber que, muitas vezes, a escolha pela paternidade ou maternidade por adoção não se dava de modo igualitário entre o casal, mas sim pelo desejo narcísico ${ }^{2}$ de um deles que "convencia" e envolvia o outro numa necessidade que era sua.

Nestes casos, o parceiro passava a assumir para si a verdade do outro, tomando e transformando um pseudo desejo em desejo real. E assim, mobilizava-se para a obtenção dos mesmos objetivos, sem se dar conta de que este não era o seu genuíno desejo, mas sim o do parceiro, chegando mesmo a elaborar argumentos apaziguadores para a sua escolha, tais como: "isso nos trará felicidade" ou "assim formaremos uma família" ou no caso de casais onde um deles já possuía um filho de relacionamentos anteriores, aquele que já exercia a paternidade ou maternidade respondia pelo outro com afirmações do tipo: "ele não viveu a paternidade" "gostaria que ele vivesse isso que eu já vivi", "ele precisa viver isso".

Esta vivência gerou inquietações e questionamentos sobre quais os aspectos que atuam na relação entre o casal que pode levar um dos parceiros a assumir como seu, o desejo do outro, em especial o exercício da paternidade ou maternidade, aspectos tão profundos na vida de cada um.

O que leva um parceiro a assumir como verdadeiro os anseios do outro? A crença na felicidade? O não decepcionar o outro? A simbiose do casal? O vínculo? E como consequência, nestes casos, como se formam os vínculos com os filhos? Aquele que assume como se fosse seu o desejo do outro, terá espaço psíquico para uma criança, para um filho?

Desejo narcísico refere-se àquele que advém de aspectos inconscientes do sujeito, a partir dos primórdios de sua história e das suas relações com o outro. 
Estes questionamentos foram se solidificando quando, por outro lado, a prática nos atendimentos com a família de crianças adotadas indicava, pela observação de comportamentos ou pela verbalização das mães em especial - possivelmente por serem elas quem buscavam e acompanhavam o atendimento para o filho "problema" - que havia uma relação direta entre o querer genuíno pela paternidade ou maternidade e as relações que se estabeleciam na vivência cotidiana com a criança.

Frases do tipo: "quem queria adotar era o meu marido, mas como ele morreu agora quero devolver a criança" (mãe de uma criança de 7 anos); "se eu soubesse que você seria assim eu não teria pegado você" (mãe de um jovem de 15 anos), "eu deixei de fazer tanta coisa por ele..." (parar de trabalhar, separação dos cônjuges - mãe de uma criança de 9 anos), "eu tentei mostrar a ele o meu amor, mas ele não percebe" (mãe de um jovem de 14 anos) além da insuportabilidade do pai ou da mãe adotivos, pelos trabalhos que os filhos Ihes dão, ameaçando-os com a sua devolução ao abrigo ou ao juiz.

Com tristeza, percebeu-se nestes trabalhos, que as crianças foram adotadas legalmente, mas não de alma.

E como consequência estas crianças passaram a apresentar, além dos problemas com a aprendizagem, inadequações comportamentais nos seus relacionamentos na escola e em casa, trazendo-lhes perdas e vivências doloridas, além da baixa autoestima, e a crença de que de fato não são bons e tem problemas, assumindo o papel de depositário dos conflitos familiares.

No desenrolar do trabalho vão se evidenciando o papel da família como contribuinte no agravamento de tais questões, muitas vezes por não adoção do filho que juridicamente foi adotado, por expectativas dos pais não correspondidas pelos filhos e por questões da subjetividade ${ }^{3}$ mal trabalhadas dos pais, e depositadas na criança como o grande culpado pelas mazelas das dificuldades familiares.

Esta realidade também pode se apresentar em crianças filhos de pais biológicos, mas trata-se aqui do caso de crianças adotivas, por ter sido nestes casos que melhor se pode observar tais situações.

No contexto das relações e interações dos casais, vários aspectos poderiam ser abordados, como a constituição da subjetividade, os diversos tipos de escolha do parceiro, os aspectos da intergeracionalidade e da transgeracionalidade, mas optou-se em ater-se na questão da formação do vínculo como ponto de reflexão, por supor que é neste universo que será possível encontrar alguns caminhos ou respostas que poderão clarificar tais interrogações.

Este artigo objetiva, portanto, a partir de um contexto psicanalítico, olhar para os aspectos que compõem a relação vincular de casais, cujo desejo pela paternidade/maternidade se manifesta em diferentes graus em cada um dos parceiros: eu quero um filho; eu não quero um filho; eu não sei se quero um filho; ou eu não quero um filho, mas aceito, tê-lo para satisfazer o desejo do meu parceiro. $O$ tema central deste trabalho refere-se mais precisamente à última categoria, o parceiro que não quer um filho, mas aceita a paternidade/maternidade, atendendo ao desejo do outro. E neste ponto abre-se a questão para a relação para com os filhos. Se este desejo dos pais não for genuíno, como fica a relação com o filho?

Subjetividade entendida aqui como o resultado das vivências psíquicas do sujeito que o constitui como ser único. Sujeito do desejo, segundo Freud, permeado pela noção do inconsciente e consciente. 
Pressupostos de que em cada uma dessas situações o vínculo com o filho poderá se constituir de forma mais ou menos fragilizada. Pressupostos, pois não se teve a oportunidade de aprofundar tal investigação na prática terapêutica dos casais, mas sim, no atendimento das crianças, em especial daquelas onde o vínculo com o filho adotivo não se constituiu de forma positiva.

\section{A prática mobilizadora}

O trabalho com os casais foi realizado em 2017 como atividade do Curso de "Família e Casal na Atualidade" do Instituto Sedes Sapientae - SP.

O grupo que participou dos atendimentos veio por indicação de duas entidades diferentes, uma o Fórum Central de São Paulo-Capital e o outro pelo GAIA - Grupo de Apoio e Incentivo à Adoção de Embu das Artes-SP, entidade sem fins lucrativos, composta por voluntários que estimulam, apoiam e orientam pessoas interessadas em adotar crianças ou adolescentes.

Importante fazer esta distinção, pois o encaminhamento feito por um órgão do sistema judiciário e outro social, influenciou na maneira como estes casais se apresentaram e se comportaram durante os encontros.

As atividades foram propostas em oito encontros cujo objetivo foi o de apresentar ao grupo, a possibilidade de refletir sobre as questões que envolvem a adoção - o imaginário dos futuros pais, as frustrações, os medos e as expectativas para a tomada de decisão - a partir da vivência de dinâmicas que possibilitaram a geração de movimentos introjetivos, levando cada um à percepção dos próprios medos e idealizações, tão natural durante esta etapa de "gestação adotiva", mas muitas vezes camuflados ou negados em razão do desejo pela paternidade ou maternidade.

Como recursos foram utilizadas fotos, elaboração de desenhos, apresentação de filmes, leitura e discussão de pequenos textos, construções coletivas, sempre utilizando alguma estratégia tendo como elemento facilitador algo concreto, para que o trabalho transcorresse num campo relaxado.

O casal que procurou espontaneamente pelo trabalho, vindos por meio do GAIA, chega descontraído e com muita vontade de se colocar e de compartilhar suas experiências. Por outro lado, o casal que vem por intermédio do Fórum chega com uma postura defendida, desconfiados, com falas preparadas e pouco espontâneas sobre a forma adequada de cuidar de uma criança, sempre em estado de alerta, como se estivessem sendo avaliados, mesmo após reforçado esclarecimento sobre a desvinculação dos encontros com o processo jurídico legal exigido pelo Fórum, que os reconhecerá como aptos ou não para adoção de uma criança.

Os nomes que aparecem nos relatos abaixo são fictícios preservando a identidade dos participantes.

No primeiro encontro compareceu somente o casal vindo pelo GAIA. Chegam ávidos para relatar a sua história. Estão há dez anos casados. Sueli, quarenta anos, tem uma filha biológica com doze anos, Ágata, fruto de um relacionamento com um antigo namorado, com quem não chegou a morar junto. Quando a filha Ágata estava com oito meses conheceu Oswaldo, hoje com trinta e nove anos, e a filha se "apaixonou por ele", segundo Sueli. Passado um ano e meio Sueli e Oswaldo se casaram. Ágata trata e considera Oswaldo como pai, apesar de relacionar-se com o pai biológico. Seu vínculo com Oswaldo é tal, que pede à mãe que retire do seu nome o sobrenome do pai biológico, e o substitua pelo sobrenome de Oswaldo. Interessante ressaltar que o próprio casal se dirige um ao outro como "pai" e "mãe". 
A decisão do casal em adotar uma criança vem após duas tentativas de gravidez interrompidas por um aborto espontâneo. Segundo Oswaldo, foram experiências muito traumáticas, principalmente o último aborto, pois a gestação já estava no sexto mês e o feto (menino) apresentava grandes deformidades. Mesmo Ágata, filha biológica de Sueli, já nasceu com problemas, e segundo os médicos, foi um milagre a sua sobrevivência.

Segundo Sueli, a partir destes abortos começou a engordar muito chegando a pesar $120 \mathrm{kgs}$. Fez a cirurgia bariátrica, e nos exames descobriram que ela era portadora de uma síndrome que a impedia de manter uma gravidez até o final.

Quando indagados sobre o que levou o casal a decidir pela adoção, Sueli diz que na maternidade estava com a filha no colo e alguém lhe perguntou se a menina era "filha da barriga ou do coração" e isso ficou guardado dentro dela. É professora e tem dois alunos adotivos, que também Ihe despertam interesse. Porém, importante ressaltar a argumentação de Sueli, em dizer que a decisão pela adoção também dizia respeito à "Oswaldo precisa passar pelo processo de ter um bebê", e mais, quer dar à filha a possibilidade de vivenciar um irmão ou uma irmã e tudo o que esta relação pode proporcionar.

Sueli relata que tem uma irmã muito próxima a ela, "daria a minha vida por ela". Acrescenta ainda na sua argumentação o "milagre" do nascimento de sua filha biológica, e se questiona sobre a missão desta menina: "será cuidar do irmão que estamos prestes a adotar?"

Oswaldo deixa que Sueli apresente todos os argumentos do porquê querer adotar uma criança, um menino, particularmente.

Cabe aqui perguntar: por que Sueli acredita ser importante Oswaldo passar pela mesma experiência que ela passou? Por que Oswaldo aceita para si esta premissa como verdadeira? Além das questões que envolvem a intergeracionalidade- "missão da filha cuidar do irmão" - que não será abordado neste trabalho.

Interessante salientar, que Sueli e Oswaldo estão vivendo um processo altamente idealizado do papel de pai e mãe, já estão com o quarto do bebê montado. Sueli fala na escola, para os seus alunos e colegas, e aos amigos, que terá um bebê do coração, como se ela estivesse prestes a dar à luz naquele momento. Levanta-se à noite para olhar o quarto da criança, como se ela já estivesse no berço demandando a sua atenção, além de levar a filha mais velha a um enorme envolvimento com o processo de adoção.

Será que Oswaldo de fato assumiu para si a paternidade como importante vivência, conforme expressado por Sueli? Sueli abriu para Oswaldo a possibilidade de, efetivamente, ser o pai adotivo de Ágata. Oswaldo de fato já adotou a menina, e fica orgulhoso com a possibilidade de ela passar a incorporar o seu sobrenome, mesmo respeitando a sua origem biológica. Mas sua conscientização sobre o seu real papel como pai adotivo de Ágata, teria Ihe dado a condição de legitimar como desejo genuíno seu, a adoção de outra criança?

No segundo encontro compareceram além de Sueli e Oswaldo, Afonso e Flavia.

Por ocasião do atendimento, Afonso estava com cinquenta anos e Flávia com quarenta e seis. Casados. Quando casaram Afonso era solteiro e Flávia já havia sido casada e tinha um filho com dezessete anos, atualmente com trinta anos, já casado.

Afonso conviveu por dez anos na mesma casa com o filho de Flávia (dos dezessete aos vinte e sete anos), até que este se casasse. Segundo Afonso esta convivência ajudou-o a amadurecer o 
seu desejo de ser pai. Há sete anos tentaram uma gravidez, mas não aconteceu. Depois, Flávia se submeteu a uma cirurgia para retirada de um câncer na tireoide, com consequente tratamento de iodo terapia, que a impossibilitou de engravidar novamente. Partiram para o método da ovulação. Foram cinco tentativas. "Todas frustradas e muito dolorosas", relatam Flávia e Afonso. Foi quando decidiram pela adoção. Querem uma menina de até um ano de idade. Afonso disse que "não precisa ser do nosso sangue para sermos felizes". Ele quer ver sua "filhinha" dar os primeiros passos, ouvi-la falar "papai" antes de "mamãe".

Interessante observar que antes de Flávia começar a se apresentar ao grupo vira-se para Afonso e pergunta baixinho "nós somos uma família, não somos"? A constituição de uma família para Flávia implica na existência de filhos em comum?

Em quase todas as falas de Flávia o marido a interrompia, como se não quisesse ter ali revelado os receios da esposa. Em vários momentos Flávia apresentou incertezas, medos e até mesmo planos pessoais, como além do exercício do trabalho, iniciar uma faculdade. Até ali, não incluíam nos seus projetos de vida as tarefas e a demanda de cuidados com um bebê. Chega a dizer, referindo-se a dispor de tempo para cursar a faculdade, que "ele (o marido) vai ter que se virar com o tempo para cuidar do bebê". Além disso, fala que hoje a sua casa não tem espaço para um bebê, fala de viagens...

Estas observações sugerem questões reveladoras sobre a ausência de espaço interno para a entrada de um bebê na vida de Flávia. Quem na verdade quer ver a 'filhinha' dar os primeiros passos, falar papai e mamãe? Parece que este é um desejo de Afonso e não de Flávia, mas por que Flávia compactua da ideia de adoção de uma menininha?

Quando Flávia fala de seus medos diz "como vou dar limites a essa criança, como se fosse meu filho", "com o meu filho foi fácil... eu dizia não, e estava acabado." Verbaliza o seu medo da revelação da adoção e na adolescência a filha querer ir embora e não a aceitar como mãe. Afonso nestes momentos tentava, na verdade, camuflar as angústias de Flávia, dizendo que tudo isso iria se resolver quando a sua filhinha chegasse.

Flávia ao se referir à filha adotiva diz "como se ele fosse meu filho" e não como Afonso, "a filhinha", evidenciando que ela não legitimou para si o seu papel de mãe desta criança, e consequentemente não poderá legitimar como sua, a filha que está prestes a adotar. E isso leva a pensar, como será que Flávia formará um vínculo positivo com esta filha que na verdade não será sua? Será realmente tão simples como afirma Afonso, que tudo se resolverá quando a sua filhinha chegar?

Embora Afonso tivesse revelado um genuíno desejo de ser pai, caberiam alguns questionamentos da ordem da intergeracionalidade, e da sua relação com o enteado, que não foi possível aprofundar em razão do objetivo do trabalho com o grupo. O que efetivamente se deu, foi que Afonso omitiu os seus medos e angústias, como se houvesse uma intenção no trabalho de interferir no processo de decisão do Fórum.

Fazendo um corte didático, vê-se que três questões direcionam para a busca de respostas: como se dá o vínculo no casal? como assumir para si o desejo do parceiro? e como estes aspectos interferem na formação do vínculo com o filho?

\section{Desejo e vínculo}

Embora o objetivo deste trabalho seja trazer uma reflexão sobre os aspectos que a prática dos encontros com os pares em processo de adoção suscitou e mais, um pensar a realidade de crian- 
ças adotadas no que se refere ao vínculo com os pais adotivos, é importante abordar alguns aspectos da teoria psicanalítica no que se refere ao desejo e complementar com o conceito de vínculo de Pecho- Rivière, em razão da importância do desejo para a formação do vínculo familiar na constituição do sujeito.

Como afirma Oliveira e al (2017): “...na perspectiva psicanalítica, a adoção diferentemente do campo jurídico, é tomada como um modo de filiação singular e simbólica por meio do desejo de nomear um filho. (p 911)"

Na narrativa dos casais, várias falas expressaram um tipo de desejo - "minha filhinha vai falar papai antes de mamãe" ou "não precisa ser do nosso sangue para sermos felizes".

A noção de desejo é um dos aspectos centrais da teoria psicanalítica. Como afirma Kehl (2006) "para Freud, todo sujeito é um sujeito porque é desejante" (p.368). E mais, para a psicanálise a adoção se dá em nome de um desejo que vem suprir uma falta.

Mas de qual desejo se trata?

Trata-se de um desejo inconsciente. E se inconsciente, é da ordem da fantasia e da aspiração. A fantasia por um estado de felicidade que mobiliza estes casais, a buscar na adoção de um filho a realização de tal desejo. É consciente o objeto deste desejo, uma criança como filho, mas de onde advém este desejo que não se manifesta da mesma forma em cada uma das pessoas que ali estiveram com o mesmo propósito.

O que esta criança irá preencher em cada uma dessas pessoas? A superação de uma incapacidade de ter um filho biológico? A crença de que uma família só se constitui plenamente quando se complementa com um ou vários filhos? Por que uma menina ou um menino? Por que uma idade pré-determinada determinada? Por que imputar ao outro a necessidade e a importância de passar pela mesma experiência vivida por alguém - a de ter um filho, ou a de desempenhar o papel de irmã? Muitas questões a serem investigadas, mas esse não é o objetivo deste trabalho.

De onde surgem os desejos inconscientes?

O desejo nasce da defasagem entre a necessidade e a demanda: é irredutível à necessidade, porque não é no seu fundamento relação com um objeto real, independente do sujeito, mas com a fantasia. LAPLANCHE E PONTALIS (2006) (p. 114)

Quando o bebê se encontra no útero, tem as suas necessidades absolutamente atendidas, alimentação, temperatura, bem-estar. Quando nasce perde esse estado de plenitude e passa a lidar com condições que exige dele um esforço ativo: o de sugar, o de respirar, o de chorar para manifestar as suas necessidades e desconfortos que nem mesmo sabe ainda como distingui-las. Não há mais um cordão umbilical que o alimenta. A partir de então, passa a desejar um regresso ao seu estado de plenitude e de prazer.

O desejo nasce, portanto, na falta, como afirma Freud. Na falta de algo que se perde nos primórdios da infância, mas que permanece nos registros mnêmicos do sujeito e sempre retorna toda vez que uma necessidade se manifestar.

Em decorrência do vínculo assim estabelecido, na próxima vez em que essa necessidade for despertada surgirá de imediato a moção psíquica que procurará recatexizar a imagem mnêmica da percepção e reevocar a própria percepção, isto é, restabelecer a situação de satisfação original. Uma moção desta espécie é o que chamamos de desejo. (Freud, p. 595) 
Desejo é, portanto, pulsão de vida como afirma Freud.

E como afirma Oliveira e al (2017), "é em nome do desejo, e no lugar de uma falta que surge a criança, seja ela adotiva ou biológica" ( $p$ 911)

E este bebê passa a depender totalmente de alguém que cuide de sua sobrevivência, normalmente a mãe (ou aquele que exerce a maternagem), que lhe oferecerá o seio, o alimento, que saciará a sua fome, e os carinhos e cuidados que saciarão a fome da "alma", do psíquico, formando o vínculo e a sensação de pertencimento.

Será a mãe que pela linguagem oferecerá o primeiro universo de significantes para a criança, a linguagem, a cultura, os afetos e os valores do seu grupo. Será a família o primeiro universo cultural desse sujeito que ao mesmo tempo é único é também do Outro, do outro social.

De qualquer forma este desejo é de fundamental importância na relação com o filho esperado, é esse desejo que vai abrir espaço para que se dê o pertencimento a este grupo familiar. Pertencimento e integração crucial na formação deste sujeito, num espaço de acolhimento, de real adoção desse novo ser, que se constituirá a partir da sua relação com o outro, e se assim o for Ihe dará uma constituição de alguém que quer e pode enquanto sujeito.

Como afirma Pichón -Rivière o vínculo é uma estrutura psíquica complexa que inclui um sujeito, um objeto e sua mútua interrelação com processos de comunicação e aprendizagem. É um processo contínuo que, ao mesmo tempo que nos transforma, transforma o outro, é na relação com o objeto que dá ao ser a sua condição humana e social.

O vínculo tem, portanto, um caráter psicossocial e envolve sempre uma relação tripartite: o eu, o outro e um terceiro que é o social, a ética, a interdição, a lei.

Por esta razão que para Pichón, o conceito de saúde pressupõe um adaptar-se de modo ativo à realidade, apreender a relação com o outro e modificá-la para si. E a doença é produzida pelo social, pela segregação familiar quando não se dá a integração e o pertencimento.

O vínculo é um aspecto que está atrelado diretamente ao desejo e daí a sua importância quando se olha para as questões familiares e de constituição de um sujeito saudável em seus aspectos intra e intersubjetivo, a importância que é para o filho perceber o que ele representa no desejo dos pais.

\section{A escolha do parceiro}

Muitas vezes ouve-se em reuniões sociais observações tais como... "como pode fulano ser casado com ciclano?" ou "o que ciclano vê em fulano?" "por que razão fulano reclama tanto de ciclano e ainda fica casado com ele?" "com tanta moça/rapaz interessante minha filha(o) escolheu justamente este(a) para se casar".

A pergunta que se apresenta é: o que leva alguém a casar com outro? Um outro específico num universo tão grande de homens e mulheres mais ou menos interessantes, conservadores... liberais, agressivos... carinhosos, ciumentos... não ciumentos, trabalhadores... preguiçosos, bem-humorados... mal-humorados, cuidadores... desleixados, seguros... inseguros, otimistas... negativistas, e uma infinidade de características recorrentes e comuns aos sujeitos. Estas escoIhas que num primeiro momento podem parecer tão enigmáticas para olhares leigos, não serão para olhares mais treinados e perceptíveis como o de especialistas e terapeutas. 
Isto porque, na escolha do parceiro, que na nossa sociedade, em sua maioria, se dá de modo espontâneo e natural, atuam fatores inconscientes de ambos os sujeitos, associados diretamente à sua identidade psíquica, a possíveis heranças intergeracionais ou transgeracionais e a fatores conscientes do amor. Por esta razão poder-se-ia dizer, que esta espontaneidade de escolha é dirigida. Há um certo direcionamento do aparelho psíquico que os magnetiza para determinados atrativos no outro, que os colocam num estado de enamoramento, por esta razão EIGUER (1989, pg. 31) afirma que "a escolha do parceiro não se faz completamente por acaso".

O processo de escolha do parceiro que EIGUER (1989) chamou de "primeiro organizador inconsciente" paradoxalmente, organiza também a angústia da castração advinda do complexo de Édipo.

No complexo de Édipo o menino disputa com o pai a mesma mulher, a mãe, objeto de amor do pai, mas, pelo tabu do incesto, como ele não pode ter a mãe como seu objeto de amor, canaliza a angústia desta castração criando uma identidade com o pai para que possa ser capaz de conquistar uma mulher que seja parecida com a mãe, e dela se enamorar. "Ele perdeu sua mãe (como parceira), mas ganhou sua liberdade (condicional) de escolher uma outra mulher", EIGUER (1989, pg. 31) e aqui se dá o paradoxo. É preciso perder para poder ganhar a liberdade, a autonomia para procurar um objeto de amor fora da família.

E desta forma buscará, na parceira, alguém com características da sua mãe, por isso se diz que a escolha da parceira é relativamente espontânea. $O$ mesmo acontece com a menina em relação ao pai. Neste sentido que a escolha dos parceiros acontece a partir de um movimento convergente entre dois mundos psíquicos que se equilibram, se organizam e se complementam formando o que EIGUER (1989), chamou de "compromissos inconscientes".

Mas será este determinismo do Édipo que condiciona as escolhas amorosas?

EIGUER (1989) apresenta diferentes modalidades de escolhas dos parceiros, salientando que esta tipificação é compartilhada por vários outros autores, mas apresentada em primeiro lugar por Freud, (1914):

- “A escolha edípica: [...]não se trata de uma identificação ativa e adulta ao pai do mesmo sexo no processo amoroso, mas de uma identificação parcial e narcisista à atitude infantil do próprio sujeito.

- A escolha anaclítica: o homem ou a mulher vão em busca de um parceiro que Ihes permita encontrar um apoio (mãe ou pai da infância), ligado à pulsão da conservação. É uma escolha regressiva em relação à etapa de dissolução do complexo de Édipo. Ela propõe uma relação complementar infantilizante para um e acentua o papel parental para o outro.

- A escolha narcisista: busca um objeto que se assemelhe à:
a) Ao que se é
b) Ao que se foi
c) Ao que se gostaria de ser
d) À pessoa que foi uma parte de si próprio", (EIGUER, 1989, p. 33)

Há ainda a escolha que EIGUER (1989) denominou de "escolha defensiva", aquela onde o parceiro não se parece em nada com a figura do pai ou da mãe, nem física nem psicologicamente, é o oposto, mas poderá ter como escolha o Édipo parental inconsciente, ou seja, um avô materno para o rapaz e a avó paterna para a moça.

Há ainda uma gama de diferentes tipos de escolha do parceiro que se poderia elencar, porém, não cabe aqui apresentar, uma vez que não é esse o foco desta discussão, mas muito mais transcorrer sobre as escolhas inconscientes individuais, que acabam por constituir o inconsciente do 
casal e, consequentemente ao da família, e de como isso é, muitas vezes, projetado e idealizado na vinda de um filho (EIGUER, 1989).

Fala-se de escolhas, que diretamente estão conectadas ao desejo, no sentido da busca do retorno a uma vivência de um estado de satisfação, à pulsão sexual, do encontro dos parceiros pelo enamoramento e pelo amor, que "requer a participação das instâncias conscientes da personalidade" (Kaës, 2011).

O processo de enamoramento leva em conta dois aspectos, o da intrasubjetividade e o da intersubjetividade. O primeiro diz respeito à constituição psíquica do sujeito, que inclui a relação com o outro e com o mundo, ou seja, uma relação intersubjetiva. Este processo se inicia a partir dos primeiros dias de vida da criança. O contato com a mãe, ou aquele que desempenha este papel, o contato com a família estrita e ampla, além de possibilitar ao bebê as experiências das sensações cinestésicas- tato, sons, odores, sabores- é quem tem a função de lhe passar as regras, os valores, as crenças, os papéis sociais e a cultura do seu grupo, dando à criança a condição de criar um significado e simbolização destas informações, quando então, passam a ser introjetadas pelo sujeito, num processo intersubjetivo, o segundo aspecto.

O sujeito se constitui no outro, ele se percebe na relação com o outro. Há, portanto, uma simbiose relacional entre o sujeito e o mundo, o que ele é e o que o constituiu consciente e inconscientemente. A maneira como o outro ou os outros participam do funcionamento psíquico do sujeito não é igual a todos, acontecem em diferentes graus de permeabilidade, podendo chegar a remodelações inconscientes de maior ou menor profundidade, o que caracteriza o sujeito como único.

E neste emaranhado de vivências internas e externas ao sujeito que ele se coloca no mundo em busca de um parceiro que se ajustará às suas necessidades e qualidades psíquicas, não como a meia laranja que se une ao outro como que por magnetismo, mas como uma engrenagem inconsciente que se ajusta a partir de um sistema de autossustentação e de equilíbrio. Muito bem aqui se coloca o conceito de "alianças inconscientes" de Kaës (1993).

"As alianças inconscientes são investiduras entre os sujeitos que dão conta do nível de ajuste e estabilização na troca de relativa homeostases narcisistas de cada polo, elemento fundamental no casal" [...] se trata de articulações entre os sujeitos, facilitadores e inibidores, inconscientes que configura o mapa do permitido e do proibido, o facilitado e o obstaculizado no vínculo" (SPIVACOW, 2011, p. 47).

Estas alianças inconscientes se manifestam no vínculo, e se mostram sob a forma como este casal se organiza e se une para realização de projetos, e aspirações que incluem em especial, a constituição de uma família. O vínculo não é a soma de duas subjetividades psíquicas, mas sim o que se forma na fusão de uma e outra, como uma terceira dimensão que é única, que se constitui "tanto pelas características do indivíduo[...] como pela característica do encontro e das interinfluências recíprocas, a interdeterminação ou bidirecionalidade que nele se joga" (Spivacow, 2011, p. 47).

"O vínculo que não é um sem o outro, e sim o conjunto que os forma e os une", (Kaës, apud Spivacow, Prólogo, p 69), envolve tanto o intrasubjetivo como o intersubjetivo, as qualidades psíquicas de um com o outro com as qualidades psíquicas do outro na relação, no encontro, nas alianças que se dão inconscientemente, no intersubjetivo. Lembrando, como já referido, que a constituição das qualidades psíquicas já inclui o outro, a família e o social.

As alianças inconscientes organizam o inconsciente do que une o casal sob a forma de aspirações e intenções conscientes: objetivos familiares, econômicos, filhos, vida em família, amigos, sexualidade e outros múltiplos interesses. (SPIVACOW, p. 67). 
Apresentam-se até este ponto algumas das variáveis que atuam na escolha dos parceiros e como se estabelece as alianças e o vínculo no casal, porém estes conceitos não parecem suficientes para elucidar a questão levantada sobre um dos parceiros assumir para si um desejo que é do outro.

Aborda-se os conceitos de sintonia e validação, de Spivacow (2011) considerando a possibilidade de clarificar a tal inquietação.

Spivacow traz o conceito de sintonia como uma possibilidade de o casal interagir de forma não violenta e não idealizada na diversidade, nas questões onde o desejo de um não corresponder ao desejo do outro, o que aqui se refere ao desejo pela paternidade/maternidade.

Sintonia significa estar no lugar do outro, de poder usar da imaginação e da criatividade para o perceber em seu universo emocional, assim como ele é, do lugar que fala, de aceitá-lo e respeitá-lo na sua subjetividade, entendendo que para isso há um limite do inconsciente do outro onde não se pode adentrar, o que Spivacow (2011) chama de opacidade.

Sintonia implica em receptividade, em troca e em identificação com o outro, mas ao mesmo tempo em discriminação. E isto só é possível acontecer no casal a partir de um estado de amorosidade e daquilo que um capta do outro de modo emocional e não intelectualmente. Isto não significa que haja somente aceitação à vontade e ao desejo do outro, mas sim, e fundamentalmente, o seu reconhecimento.

Porém, se houver aceitação e reconhecimento, se dará o que Spivacow (2011) denomina de validação, de legitimação do que se capta do outro tal como é, sem pretender modificá-lo, sem que se faça um acordo e principalmente sem que haja submissão daquele que aceita, e aí sim, o desejo de um passa a ser o desejo do outro, de forma genuína e consciente.

\section{Vínculo com o filho}

Este universo relacional, sujeito/outro, sujeito /mundo caracterizará o homem como um ser social, que se compõe a partir de quando, onde, com quem e como vive. Isto o constituirá na intrasubjetividade e na intersubjetividade.

A constituição de um sujeito, com uma estrutura psíquica saudável, passa, necessariamente, pela maneira como vivenciou os seus primeiros contatos com o mundo.

Intervém nesse processo a maneira como esta criança chega à família, se corresponderá ou não ao real desejo dos pais - seja por estes quererem ou não um filho, seja pela expectativa destes em relação ao sexo desta criança ou pelo momento não esperado para assumir a paternidade/maternidade - além da estrutura física e psicológica da família que possa lhe dar continente, afeto, amor e confiança, fundamentais em sua constituição psicológica, de modo a Ihe oferecer melhores recursos para, no futuro, relacionar-se, fazer escolhas, desempenhar os papéis sociais, lidar com suas frustrações e desenvolver a autonomia, fundamental inclusive nos aspectos da aprendizagem.

No trabalho com crianças, foi possível observar o quanto os aspectos relacionados ao vínculo contribuem para a sua fragilidade psicológica e consequente manifestação de dificuldades relacionais, de comportamento e de aprendizagem. Em grande parte dos casos, os entraves se apresentavam na família, mas protagonizado pela criança que carecia de confiança, do sentimento de pertença, de uma estrutura familiar de apoio e sustentação psíquica. 
Ao trabalhar com as famílias em processo de adoção, se evidenciou a problemática do desejo por um filho não se manifestar com a mesma intensidade entre os parceiros ou ainda a não existência de um espaço psicológico para a entrada de uma criança na vida de pelo menos um dos parceiros. Isto suscitou a possibilidade de se estabelecer a correlação entre a fragilidade do vínculo entre os pais e filhos, percebida no trabalho com as crianças, poder estar associada aos aspectos da sintonia e não validação por parte de um dos pares, do desejo do seu parceiro(a), em tornar-se pai/mãe.

Este trabalho é conduzido associando o tema do desejo ou a validação de um desejo, Spivacow (2011), no caso pela paternidade/maternidade, e o vínculo. Salientando que a fragilidade do vínculo entre pais e filhos biológicos já traz perda para as crianças, e mais ainda para as crianças adotivas, cujo processo de formação da sua subjetividade já sofreu a interferência de vários fatores correlacionados ao sentimento de pertença.

Muitas vezes um casal que tem filhos biológicos e adotivos quando questionado quanto ao número de filhos que tem, ouve-se a seguinte resposta: "tenho dois e um de criação".

O que é um filho de criação? É alguém a quem se deu teto e comida, escola, médicos, cumpriu o seu papel de caridade tirando uma criança da rua, do frio, da fome, dos maus tratos e do risco? Como será para esta criança adotada, ouvir ser "filho de criação"? Ele não é filho... somente está no lugar de um filho? O não ser... não pertencer sempre traz marcas que dizem respeito à sua origem, à sua identidade, ao seu valor, que geram desdobramentos psicológicos negativos passíveis de acompanhá-lo por toda a sua vida. Muitas vezes este sentimento pode gerar uma posição de eterna gratidão àqueles que o acolheram ou, ao contrário, gerar um sentimento de hostilidade e ressentimento por não ter sido de fato acolhido de alma. Segundo Oliveira et al (p 910) “(...) todo sujeito, seja ele biológico ou adotado juridicamente necessita ser adotado no desejo do par parental que o acolheu, elegeu e o nomeou como filho."

No universo de fantasias dos pais adotantes, se pode ouvir: "como será que vou dar limites para esta criança tão carente?" "Fiz isso com o meu filho..., mas como tratar esta criança como se fosse o meu filho?" O "como se", já dá ao outro, à criança ou jovem, uma condição de quem não é, daquele que não tem família, não tem origem, e se ele não pertence, pode, a qualquer momento, entender a possibilidade de ser descartado. Voltar ao abrigo, voltar à rua, voltar ao desamor.

Por esta razão que quando se lida com crianças ou jovens que apresentam comportamentos agressivos, comportamentos que o colocam em extremo estado de risco (drogas, fugas, roubos, prostituição ou até mesmo tentativas de suicídio) questiona-se se eles não estariam colocando os pais em xeque para poder entender o seu lugar no desejo desses pais.

O limite e o afeto dão à criança a condição de se sentir seguro e de desenvolver a afetividade. Dão a ele uma condição de valoração de si próprio e do social. É como se implicitamente fizessem a pergunta aos pais adotivos: vocês me amam o suficiente para suportar tão dramáticas e angustiantes situações, ou vão me descartar?

Estas crianças adotadas acabam passando por duplo processo de rejeição, o abandono pela mãe biológica e agora o risco (mesmo que fantasioso) de ser abandonado novamente pela família que o adotou? Esta dúvida pode permanecer no universo fantasmagórico do sujeito por muitos anos.

Como se constitui esta criança que se privou dos primeiros contatos com a mãe biológica, ou sofreu maus tratos e abandono, quais os mecanismos de defesa que ela cria para, de fato, depo- 
sitar no outro a confiança de que não será novamente traída e constituir um vínculo que lhe dê sustentação psíquica?

São crianças que sofreram a dor do abandono, que buscam uma explicação para tal rejeição, como a história de um paciente que relatou que gostaria de encontrar a sua mãe biológica para perguntar "por que você fez isso comigo?" A dor que este jovem vive pela lacuna de uma resposta que lhe possa aquietar, que lhe dê a condição de dar sentido à sua dor, e constituir a sua identidade, permeia todas as esferas da sua vida afetiva e social. Por outro lado, neste mesmo caso, a atuação da família, que por mais que busque ajudá-lo, coloca-o inconscientemente, fora do grupo familiar, mesmo que fisicamente junto, impetrando a ele a causa dos conflitos e da desorganização familiar.

Na verdade, a todo momento, de uma forma ou outra, este sujeito é lembrado que não pertence àquele grupo e por causa dele há um desajuste e um desequilíbrio familiar, quase sempre manifesto pela agressividade.

Esta situação gera no sujeito um movimento persecutório e vitimado. Ou... "eles são tão bons para mim e eu não correspondo", ou "eles não gostam de mim porque eu não sou bom o suficiente", "ou eles podem me abandonar como eu já fui abandonado no passado", até porque muitas vezes esta ameaça velada é presente e constante em seu cotidiano. Este aspecto pode gerar um movimento de autodefesa, de isolamento que favorecem, inclusive, um distanciamento das questões da aprendizagem. Angústias fantasmagóricas acompanham a vida dessa criança ocupando grande parte do seu pensamento. E assim sendo, fica pouco espaço mental para a curiosidade pelo aprender.

Este sentimento de não valoração agrega uma crença de não merecimento, que se manifestará, como já dito, na constituição de seus laços afetivos e na crença de uma incapacidade de aprender.

Casos em que são delegados ao filho adotivo todas as mazelas dos fracassos, e das escolhas dos pais... "eu deixei de trabalhar para cuidar dele" ... "eu deixei de estudar para estar com ele", "eu perdi o meu marido pelos maus comportamentos dele". O adulto que não consegue perceber que as escolhas foram suas, as frustrações são suas e ao filho é imputado e cobrado, a responsabilidade pela sua infelicidade. E mais uma vez, para a criança fica o sentimento de que não é bom o suficiente para ter direito ao amor incondicional desta família que o acolheu, podendo gerar um sentimento de que está ali por um favor desses pais que o acolheram e não por ter sido desejado.

Normalmente quando um casal decide pela adoção de um filho, em grande parte dos casos, já tentaram ter o seu filho biológico. A criança adotiva estará a todo momento, representando a "incapacidade ou o fracasso", como diz LEVINZON (2000) a "ferida narcísica" ${ }^{4}$ normalmente do parceiro estéril, "exigindo a renúncia definitiva de um projeto pessoal de vida".

Correa (2014) citando Freud em Toten e Tabu (1913) aborda a forte relação do desejo pela paternidade/maternidade e a constituição psíquica de um filho.

(...) sua majestade o bebê é o herdeiro dos sonhos e desejos não realizados dos pais, o narcisismo da criança fica ancorado em cima destes desejos" "É ponto crucial a partir do qual o sujeito, no processo de subjetivação, deverá assumir o seu lugar e se apropriar do sentido de seu próprio desejo em relação aos seus predecessores. (CORREA, O.R., 2014, p. 42).

\footnotetext{
4 As marcas do sofrimento ou traumas imprimidas no sujeito quando da constituição da sua subjetividade.
} 
Outras vezes, casais que perderam um filho e precisam de alguém que ocupe este lugar, pela dor da ausência, pela dor da falta. A pergunta que se faz é... qual o lugar que esta criança irá ocupar no inconsciente desses pais? Quais as expectativas que terão em relação ao filho adotivo? O quanto ele terá que se esforçar para preencher os anseios narcísicos da continuidade do eu paterno ou materno, que almeja no filho alguma coisa de seu, como "um pedaço de mim"?

Qual o papel da criança que é gerada para doar uma parte de si para um irmão enfermo e esta doação não tem êxito? Carregará a culpa pela morte do irmão, da sua incapacidade de salvar o outro? Da sua incapacidade de corresponder a uma expectativa dos pais? Sem dúvida que a resposta a estas perguntas passará pela relação pais e filho, pelo vínculo, pela intergeracionalidade.

Como se dará a relação de vínculo entre pais e filhos adotivos considerando as frequentes dúvidas nos pais aspirantes? Um mundo fantasmagórico de medos e incertezas acompanharam o trabalho com o grupo de pais adotantes. As colocações aqui expressas foram verbalizadas, ou subtendidas a partir de manifestações inconscientes dos participantes nos encontros.

"Qual a carga genética desta criança, quais doenças ele poderá apresentar?" "Será uma pessoa má?" "Será uma pessoa louca?" "Poderá me matar um dia, já ouvi tantos casos...?" E quando de fato alguns comportamentos saem do padrão esperado do bom filho, a pergunta que se apresenta é: "se fosse o meu filho biológico, estaria me dando este trabalho?... e a resposta, também imaginária, provavelmente, será não".

A revelação dos medos de que o filho adotivo venha a sofrer preconceitos. Os medos de exercer a paternidade, o limite, ou a maternidade, o afeto, e um dia ser traído pela busca, especialmente na adolescência, de sua origem biológica "e se ele quiser ficar com a sua mãe verdadeira e me largar", "se ele me perguntar sobre a sua origem só na adolescência e eu contar que ele é filho do coração, tenho medo de que vá embora".

Estes são medos genuínos da entrega, da entrega do amor por um filho que, muitas vezes, podem acreditar não lhe pertencer genuinamente, apesar de amá-lo incondicionalmente, muitas vezes. Esse filho pertence à outra pessoa que deverá estar sofrendo muito, que poderá reivindicá-lo de volta. Como será no futuro se ele me abandonar para ficar com a sua família biológica? É melhor que haja uma proteção e não o amar tanto, é melhor não ser muito rígido impondo limites, "e se ele não me aceitar como mãe", "e se ele não aceitar a autoridade paterna".

Este panorama faz com que, muitas vezes, os pais adotivos sejam muito permissivos e protetores, com medo de gerar mais uma frustração em alguém que já sofreu tanto ou, e por medo de perdê-los e virem a sofrer, amam com restrição.

Evidentemente que isto não é regra. Muitos são os casos de adoções bem-sucedidas, de filhos e pais adotivos legítimos. Lembrando que o ato de adotar também pode não ocorrer com o filho biológico, gerando os mesmos sentimentos de rejeição e abandono das crianças que foram, de fato, adotadas.

Somos todos pais e filhos adotivos. Mesmo gerando filhos biológicos, precisamos 'adotar' a criança real que nasce, que é diferente - em maior ou menor grau - do filho dos sonhos e dos desejos; por seu lado, os filhos - mesmo os biológicos - precisam 'adotar' os pais reais, que também são diferentes dos pais de seus sonhos e desejos. (Bernard This, in MALDONADO, M.T.,1997, p. 99).

Nestes casos, onde a adoção efetivamente acontece, com certeza o vínculo, que é a "matriz de todo afeto", Correa (2014) se efetivará como base estruturante e organizatória do sujeito. 


\section{Considerações finais}

$\mathrm{Na}$ busca de referenciais teóricos que indicassem caminhos elucidatórios sobre os aspectos existentes na relação de um casal, aspectos estes capazes de mobilizar o outro a aceitar para si um desejo que não é seu, encontrou-se em EIGUER (1989) e SPIVACOW (2011) conceitos e proposições, com base psicanalítica, que conduziram a esclarecimentos e possibilidades de ampliação de tais reflexões.

Sem dúvida que buscar compreender a maneira como um casal se organiza num espaço de interação onde estão presentes duas subjetividades distintas, que os mobilizam nas suas escolhas, nas definições de prioridades em seus projetos de vida, de como pensam e buscam constituir a família, filhos, como se organizam nas tarefas, no exercício e distribuição de papéis familiares e sociais, é preciso primeiro entender a origem deste casal, de como este par se formou, de como se escolheu, quais as questões da subjetividade de cada um que se conectou ao outro, os aspectos inconscientes da escolha e o que conscientemente os levou ao enamoramento.

Este universo único do casal, é um encontro de alianças inconscientes que os une, os organiza sem que nem mesmo eles próprios a conseguem definir com clareza. Sábio o velho ditado que diz "em briga de marido e mulher não se mete a colher", pois "meter a colher" significa inferir uma lógica racional num espaço nebuloso do inconsciente.

Porém, reconhecer que as alianças inconscientes organizam o casal, não bastou para elucidar tais inquietações.

Buscou-se no conceito de vínculo tais respostas, "espaço de investidura de dois ou mais sujeitos [...] configuram um encontro" (Spivacow, 2011, pg 68). Encontro que se dá a partir das alianças inconscientes que os conduzem na manifestação de suas aspirações e desejos que inclui a constituição familiar e os filhos. Mas observou-se, no trabalho com os casais adotantes, que só o vínculo entre eles não deu conta de justificar, nem mesmo demonstrar, uma manifestação igualitária dos parceiros pelo desejo por um filho.

A elucidação de tal questão se apresentou no conceito de sintonia validante proposto por Spivacow (2011), na possibilidade de um parceiro legitimar o desejo do outro e o assumir para si de modo consciente, e assim poder entender que o desejo de Sueli foi de fato legitimado por Oswaldo, na medida em que Sueli também o legitima como pai de sua filha biológica. E, ao contrário, Flávia, embora dissesse também querer a filha tão desejada por Afonso, não validou o desejo do marido, e isso pode-se verificar na manifestação de seus medos, de se referir à "filhinha" "como se" fosse a sua filha e muito marcadamente pela ausência de espaço interior para uma criança em sua vida até aquele momento.

Por outro lado, pode-se estabelecer a correlação dos conceitos de sintonia validante, (Spivacow,2011 p136), com as questões vivenciadas na prática terapêutica com as crianças e jovens, onde esta legitimação não se deu, e como consequência, o vínculo entre pais e filho ficou fragilizado, gerando grandes danos na vida psicológica e social destes sujeitos.

Evidenciou-se na teoria o que a prática dos atendimentos já sugeria, que há uma correlação direta entre a escolha dos parceiros, mobilizada pelo universo inconsciente de cada um dos pares, a maneira como se vinculam como casal, como se organizam quanto ao respeito e legitimação dos desejos de cada um, pelo mecanismo da sintonia e validação, muito particularmente quando o desejo se refere a ter ou não um filho, e a configuração do vínculo pais e filho, em especial com um filho adotivo. 
Quando há de fato a validação do desejo de ser pai ou mãe por um dos parceiros e o outro for capaz de reconhecer e legitimar este desejo, muito provavelmente este filho será bem-vindo, com chances de efetivar um vínculo positivo e forte com os seus pais.

Enfatiza-se finalizando, a importância das instituições jurídicas e sociais envolvidas com as questões da adoção, abrirem espaço e incentivarem os futuros pais a participarem de um trabalho prévio de sensibilização, reflexão e aprofundamento de questões tão cruciais, para que o sujeito possa desenvolver um movimento reflexivo e subjetivo sobre o papel que irá assumir como pai ou mãe adotivo. Do real significado para si de tal decisão, da constituição e das implicações da formação de um vínculo positivo entre pais e filhos, da importância da família. Talvez assim minimizariam problemas futuros que, muitas vezes, culminam com a devolução de crianças aos abrigos, crianças estas já em processo de adaptação nas famílias adotantes, reforçando as sequelas da vivência de duplo abandono. 


\section{Referências}

CORREA, O.R. - Os Avatares da Parentalidade, 2013, in LEVINSKY, B., GOMES, C., FERNANDES, A, Diálogos Psicanalíticos sobre Família e Casal, cap 3, vol 2, As vicissitudes da família atual. São Paulo: Zagodoni Ed, 2014.

EIGEUR, A. - Um divã para a família. Porto Alegre: Artes Médicas, 1985

FREUD, S. - A Interpretações dos Sonhos. Obras Psicológicas Completas de S. Freud, vol V. RJ: Ed Imago,1969.

LAPANCHE, PONTALIS - Dicionário de Psicanálise. São Paulo: Martins Fontes, Ed., 2001

KEHL, MR. - O Desejo da Realidade in NOVAES, A. O Desejo. São Paulo: Cia das Letras,2006

LEVINZON, G.L. - A Criança Adotiva na psicoterapia psicanalítica. 2ae ed. São Paulo: Ed. Escuta, 2000

MALDONADO, M.T. - Os Caminhos do coração: pais e filhos adotivos. 3ảed, São Paulo: Saraiva, 1997

MOGUILLAMSKY, E, NUSSBAUM, S.L. Psicanálise Vincular - Teoria e Clínica Vol 1 - Fundamentos Teóricos e Abordagem clínica do Casal e da Família. São Paulo: Zagodoni Ed, 2011

OLIVEIRA, P.A.B.A., \& SOUTO, J.B. (2017) - Adoção e psicanálise: a escuta do desejo de filiação. Psicologia: Ciência e Profissão, 37(4),909-922.https:??doi.org/10/1590/1982-3703003672016

SANCHES, P.R.P. A alteridade na conceituação freudiana de desejo e pulsão, in Revista Brasileira de Psicanálise, vol 44, no 4, São Paulo, 2010,http://pepsic.bvsalud.org/scielo.php?script=sci arttext\&pid=S0486641X2010000400009,04/11/2017, 15:40hrs

SPIVACOW, M.A. La pareja em conflito, Aportes psicanalíticos.1a ed. Buenos Aires: Paidós, 2011 